\title{
Leishmaniose tegumentar americana no Litoral Norte Paulista, período 1993 a 2005
}

\author{
American cutaneous leishmaniasis on the northern \\ coastline of the State of São Paulo, 1993 to 2005
}

\author{
Maria Lúcia Fadel Condinoํㅜ Eunice Aparecida Bianchi Galati², \\ Márcia Moreira Holcman', Maria Rafaela Braga Salum ${ }^{3}$, \\ Diogo Correa da Silva ${ }^{3}$ e René Antonio Novaes Júnior ${ }^{3}$
}

\begin{abstract}
RESUMO
A leishmaniose tegumentar americana adquiriu caráter epidêmico no Litoral Norte Paulista, desde a década de 1990. A partir de dados secundários, realizou-se estudo descritivo da doença no período de 1993 a 2005 nos quatro municípios que compõem a região e analisou-se a frequiência dos flebotomíneos capturados nos locais prováveis de transmissão. Foram notificados 689 casos autóctones de leishmaniose tegumentar, com casos isolados e agrupados, determinando uma distribuição espacial heterogênea, com sincronismo na manifestação e ciclicidade, em intervalo de seis a oito anos. Todas as faixas etárias foram acometidas, com ligeiro predomínio do sexo masculino, sem associação com uma ocupação. Capturou-se 2.758 flebotomíneos e a espécie Nyssomyia intermedia predominou (80,4\%), no peri e intradomicílio. A doença apresentou perfil de transmissão peri e intradomiciliar, entre o periurbano e a mata, e no interior da mata. Neste caso, a transmissão estaria mais relacionada com os focos enzoóticos.
\end{abstract}

Palavras-chaves: Leishmaniose cutânea. Análise espacial. Epidemiologia. Flebotomíneos. Sistema de informações geográficas.

\begin{abstract}
American cutaneous leishmaniasis acquired epidemic characteristics on the northern coastline of the State of São Paulo beginning in the 1990s. From secondary data, a descriptive study of the disease in the four municipalities making up this region over the period from 1993 to 2005 was conducted. The frequency of phlebotomine capture in the probable transmission locations was analyzed. 689 autochthonous cases of cutaneous leishmaniasis were notified, with single and grouped cases, thus determining that the spatial distribution was heterogenous. There was synchronism and cyclicity of disease manifestation, at intervals of six to eight years. All ages were affected, with slight predominance among males, without association with any specific occupation. Among the 2,758 phlebotomines captured, Nyssomyia intermedia predominated ( $80.4 \%)$ inside homes and in areas surrounding them. The disease presented a transmission profile inside homes and in areas surrounding them, between the urban fringe and forests, and inside forests. In such cases, transmission would be more related to enzootic foci.
\end{abstract}

Key-words: Cutaneous leishmaniasis. Spatial analysis. Epidemiology. Phlebotominae. Geographic information systems.

A leishmaniose tegumentar americana (LTA) apresentase como importante problema de saúde pública pela ampla distribuição geográfica, elevada incidência, manifestações clínicas graves que podem causar lesões e mutilações severas e permanentes. Além disso, os diferentes padrões epidemiológicos que apresenta, em função das espécies vetoras, reservatórios, agentes etiológicos e interação do homem nesta biocenose, dificultam a elaboração de um programa de controle eficaz ${ }^{6}$.

A transmissão das leishmanioses é influenciada frequientemente por fatores ambientais, demográficos, comportamento humano e mudanças nos habitats dos reservatórios e vetores ${ }^{15}$. A deterioração das condições socioeconômicas da população em áreas endêmicas, aproxima o homem suscetível dos vetores e reservatórios naturais, favorecendo a instalação de surtos ${ }^{261315}$. No Estado de São Paulo, observa-se aumento anual da incidência e expansão para novas áreas de transmissão, em ambiente silvestre ou com alteração antrópica, nas áreas rurais e periurbanas, caracterizado por casos isolados, intercalados por surtos epidêmicos ${ }^{22}$.

O Litoral Norte, até a década de 1980, caracterizava-se como área de transmissão hipoendêmica para LTA, com registro de

1. Superintendência de Controle de Endemias, Taubaté, SP. 2. Departamento de Epidemiologia, Faculdade de Saúde Pública, Universidade de São Paulo, São Paulo, SP. 3. Instituto Nacional de Pesquisas Espaciais, Divisão de Sensoriamento Remoto, São José dos Campos, SP.

Endereço para correspondência: Dr ${ }^{a}$ Maria Lúcia Fadel Condino. Av. Nove Julho 372, 12020-200 Taubaté, SP.

Tel: $55123632-7583$

e-mail: luciafadel@sucen.sp.gov.br

Recebido para publicação em 12/12/2007

Aceito em 14/10/2008 
raros casos isolados ${ }^{3}$. A não ocorrência de casos no período dos desmatamentos da Mata Atlântica para a construção da Rodovia Rio-Santos corrobora o caráter de transmissão recente na região $0^{13} 20$.

A partir da década de 1990, a doença manifestou-se de forma epidêmica em todos os municípios, atingindo moradores das próprias localidades de transmissão, ambos os sexos e crianças menores de quatro anos ${ }^{324}$.

0 presente trabalho teve como objetivo analisar a distribuição espacial, temporal e atributos pessoais da endemia no Litoral Norte do Estado de São Paulo, que poderão subsidiar as ações do programa de vigilância e controle da LTA.

\section{MATERIAL E MÉTODOS}

A área de estudo situa-se no Litoral Norte Paulista, distante $220 \mathrm{~km}$ da Cidade de São Paulo e é constituída por quatro municípios: Caraguatatuba $\left(23^{\circ} 29^{\prime} \mathrm{S}\right.$ e $\left.45^{\circ} 25^{\prime} 0\right)$, Ilhabela

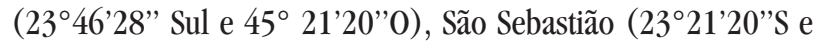
$\left.45^{\circ} 21^{\prime} 00^{\prime \prime} 0\right)$ e Ubatuba (2326'13”S 4504'08”0) (Figura 1). A área destinada à ocupação urbana localiza-se em uma estreita faixa delimitada pela Serra do Mar e o oceano. A população fixa dos municípios é de 93.226 habitantes em Caraguatatuba, 25.317 habitantes em Ilhabela, 73.296 habitantes em São Sebastião e 85.616 habitantes em Ubatuba. A região apresenta população flutuante formada por turistas ou de segunda residência, estimada em 1.450.000 habitantes ${ }^{9}$. No verão, as temperaturas são superiores a $24^{\circ} \mathrm{C}$ e no inverno, variam entre $17^{\circ}$ e $20^{\circ} \mathrm{C}^{19}$.

A atividade econômica está baseada no setor terciário, como a prestação de serviços e comércio, voltados para o turismo. 0 desenvolvimento agrícola é limitado pela feição geográfica e pela extensa área de proteção ambiental $(80 \%)$ da região ${ }^{19}$.

A presente abordagem compreende estudo descritivo, retrospectivo da LTA autóctone, no Litoral Norte Paulista, no período de 1993 a 2005. As informações foram obtidas das fichas de investigação epidemiológicas (FIE) da Secretaria de Estado de Saúde-Caraguatatuba. Analisou-se as seguintes variáveis: município e localidade provável de infecção (LPI), idade, sexo, ano de notificação, tempo de moradia na LPI, tipo de lesão, número de moradores na residência que adquiriram LTA no período de estudo e ocupação do paciente, não necessariamente por ocasião da infecção. Quando não constou na FIE a informação da variável, esta foi categorizada como ignorada.

Os anos foram agrupados em três períodos de acordo com a incidência de casos. 0 primeiro período epidêmico compreendeu 1993 a 1996, período endêmico ou inter-epidêmico, 1997 a 2001, e segundo período epidêmico, 2002 a 2005.

A comparação do número de casos, entre os períodos epidêmicos e entre sexos e período de notificação, foi realizada pelo teste estatístico do $\chi^{2}$. Na análise do tempo de moradia,

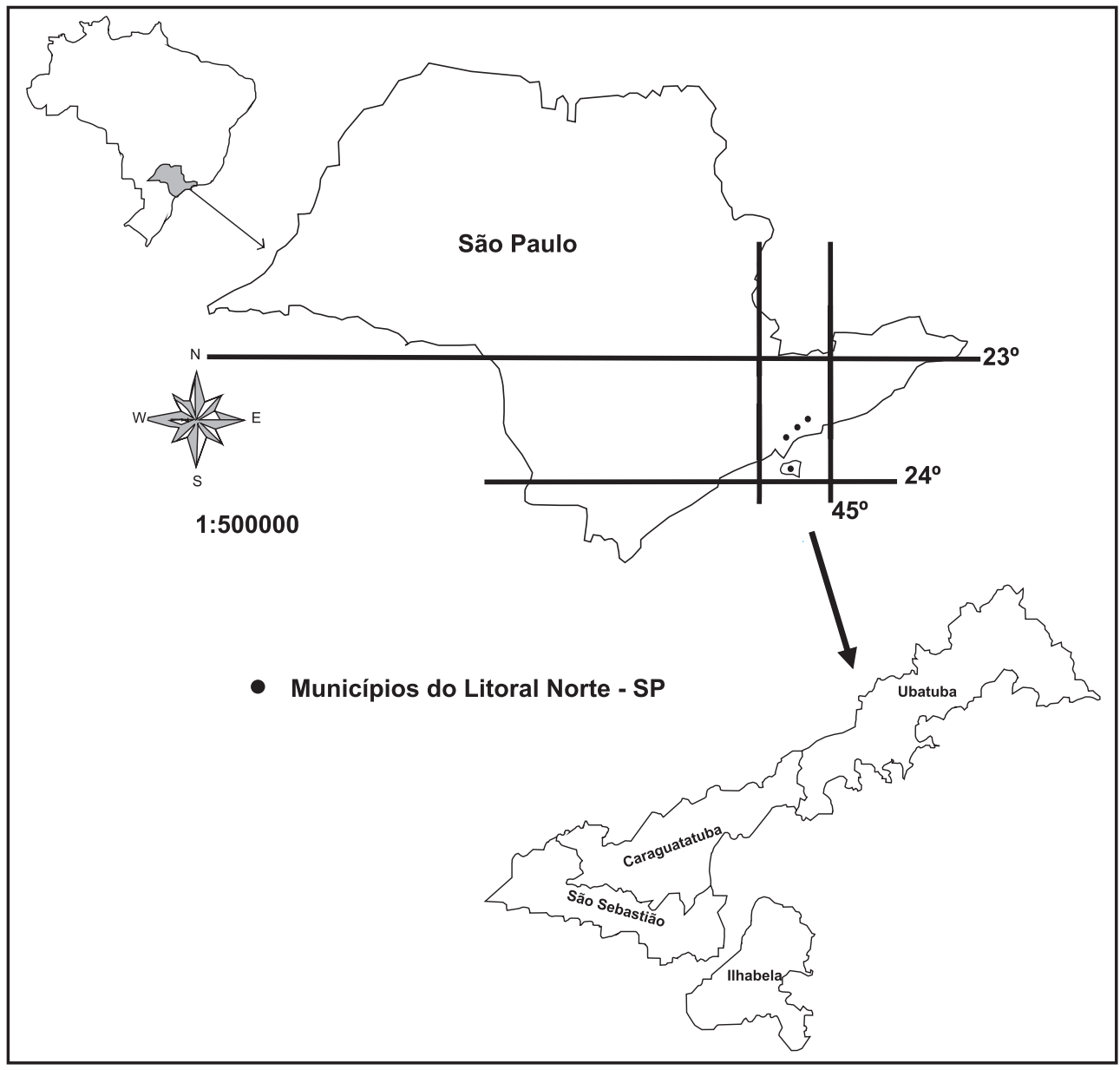

Figura 1 - Municípios do Litoral Norte Paulista, Estado de São Paulo, Brasil. 
foram excluídos os indivíduos com menos de 10 anos de idade. 0 coeficiente de incidência anual foi calculado utilizando-se o número de casos notificados no ano e multiplicado por 100.000 .

Os dados entomológicos, como número de exemplares de flebotomíneos, espécies e local de captura foram obtidos nos boletins de captura entomológica da Superintendência de Controle de Endemias (SUCEN). A nomenclatura dos flebotomíneos seguiu Galati $^{10}$.

Os casos foram georreferenciados, segundo bairro e município provável de infecção, utilizando-se o Sistema de Informação Geográfica (SIG). Os polígonos georreferenciados dos bairros foram obtidos na Secretaria Municipal de Planejamento em São Sebastião, Seção de Cadastro em Caraguatatuba, Secretaria do Meio Ambiente em Ilhabela e Ubatuba. Posteriormente, os casos foram plotados por meio do programa SPRING-Versão 4.3, desenvolvido pelo Instituto Nacional de Pesquisas Espaciais.

\section{RESULTADOS}

Foram notificados 689 casos autóctones de LTA no período de 1993 a 2005, Caraguatatuba (81), Ilhabela (229), São Sebastião (164) e Ubatuba (215). Os coeficientes de incidência mais elevados foram observados em Ilhabela e Ubatuba (Figura 2). Em 1992, não houve notificação de casos e em 1993, foi registrado o primeiro surto.

Nos quatro municípios, ocorreram duas epidemias sincronicamente, uma no início da década de 1990 e outra, nos primeiros anos do século 21, com intervalo entre os picos de 6 a 8 anos (Figura 2).

A diferença entre o número de casos incidentes nos períodos epidêmicos e no período de intervalo, foi estatisticamente significante $(\mathrm{p}<0,001)$ em três municípios, não sendo evidente em São Sebastião ( $p>0,05)$. Em todos os municípios, a ocorrência foi um pouco maior no sexo masculino; porém estatisticamente significante, somente em Ilhabela $(\mathrm{p}<0,01)$ e São Sebastião $(\mathrm{p}<0,001)$, no segundo período epidêmico. A idade dos pacientes variou de 3 meses a 86 anos.

No Litoral Norte, a manifestação da LTA foi heterogênea, em focos descontínuos com proximidade entre as localidades com maior número de casos.

Em Ubatuba, a epidemia teve início na divisa com o município de Paraty. Em três áreas, observou-se maior concentração de casos: a primeira, na divisa com o Estado do Rio de Janeiro, a segunda, próxima à rodovia que dá acesso ao Vale do Paraíba, e a terceira, em bairros periféricos do município. Não se evidenciou contigüidade com Caraguatatuba, e o número de casos por localidade foi maior que nos demais municípios. No segundo surto, houve aumento no número de casos e expansão da doença para novas áreas (Figura 3).

Em Caraguatatuba o maior número de casos ocorreu em região mais afastada do núcleo urbano, na divisa com São Sebastião (Figura 4).

A maior freqüência de casos de ITA em São Sebastião deu-se inicialmente, na região mais populosa, na divisa com Caraguatatuba e avançou para a região sul nos anos seguintes (Figura 5).

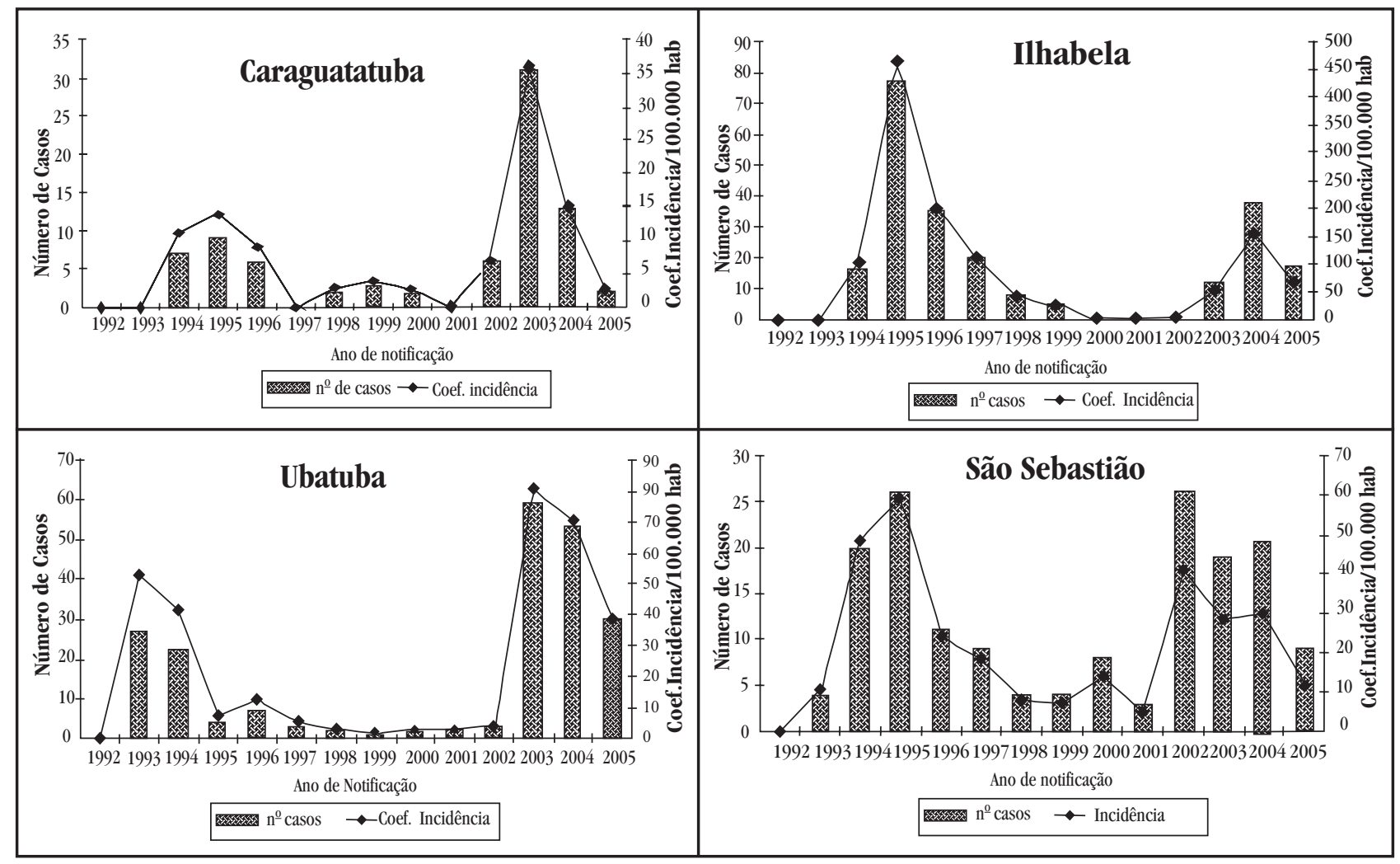

Figura 2 - Número de casos e coeficiente de incidência de leishmanioe tegumentar americana, municípios do Litoral Norte, segundo ano de notificação. 


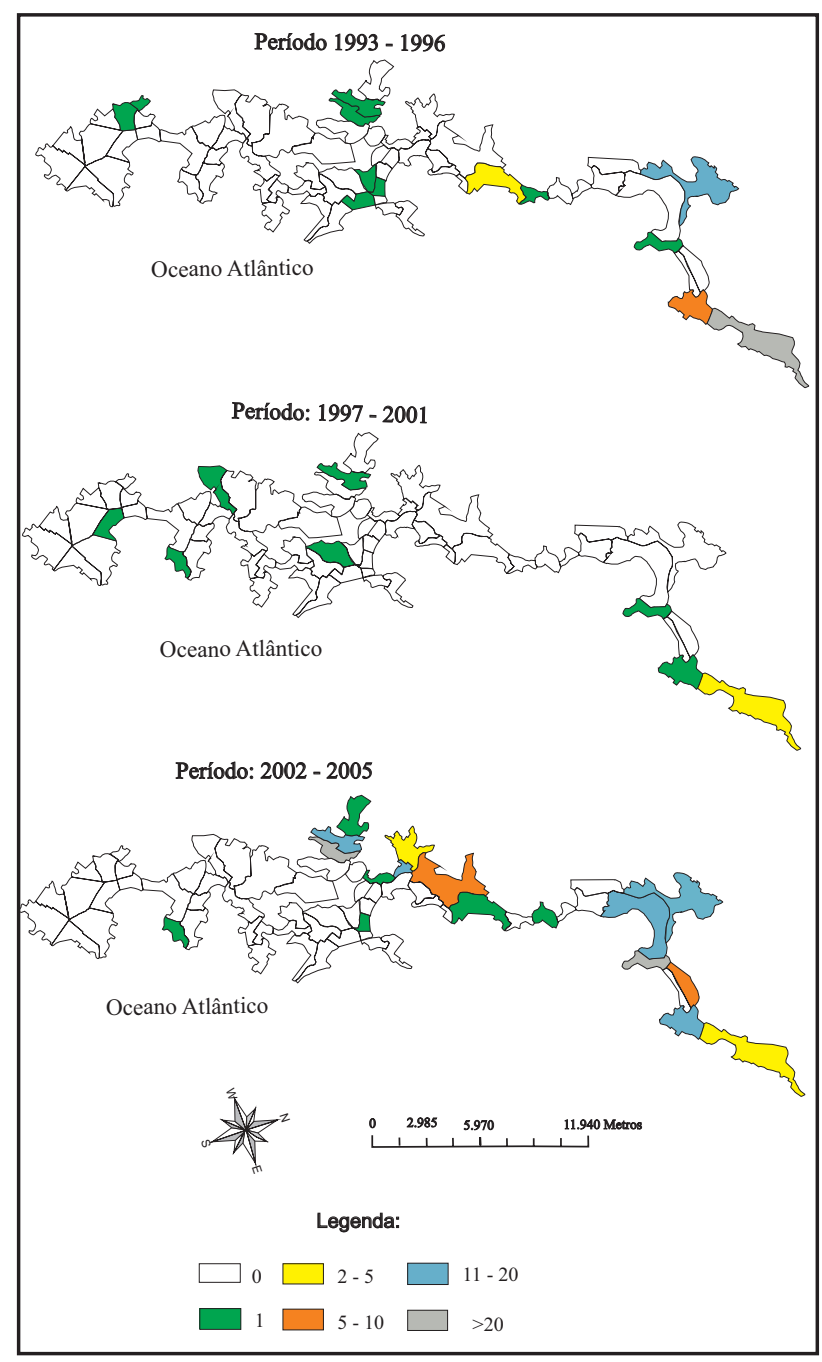

Figura 3 - Frequîência de casos de leishmanioe tegumentar americana, segundo periodo, município de Ubatuba, Estado de São Paulo, Brasil.

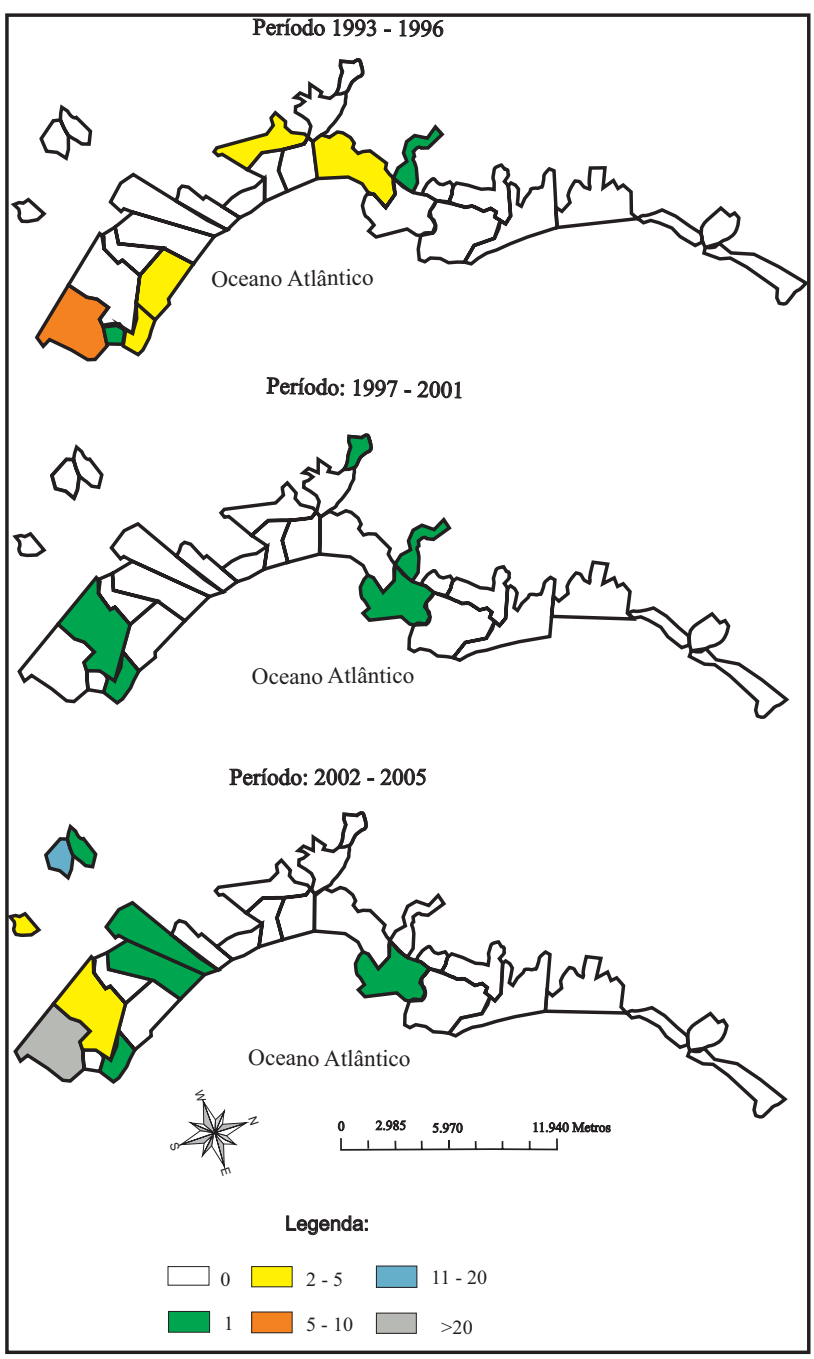

Figura 4 - Frequiência de casos de leishmanioe tegumentar americana, segundo período, município de Caraguatatuba, Estado de São Paulo, Brasil.

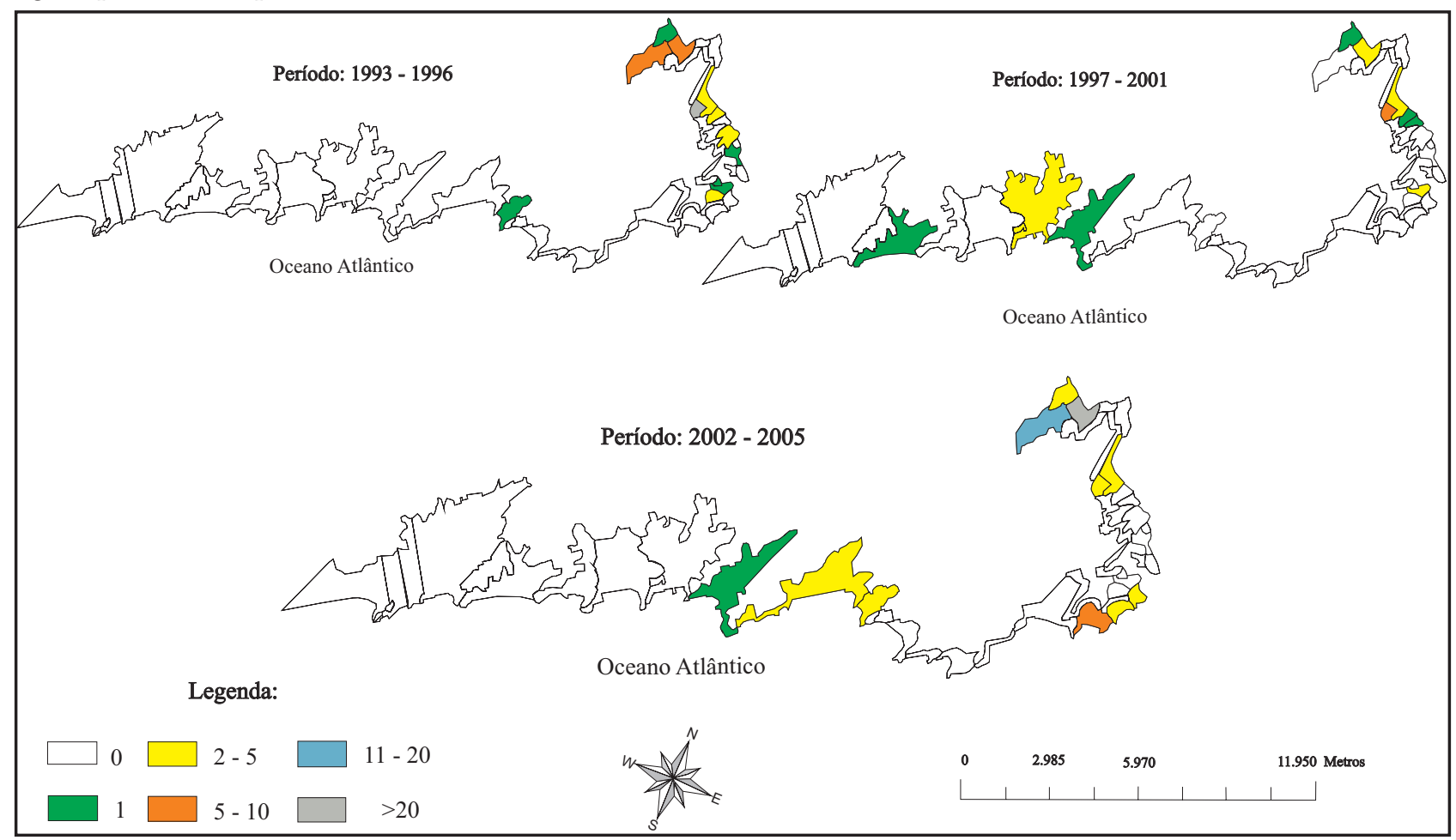

Figura 5 - Freqüência de casos de leishmanioe tegumentar americana, segundo período, município de São Sebastião, Estado de São Paulo, Brasil. 
Em Ilhabela, a infecção ocorreu predominantemente na região mais populosa, porém, houve casos em dois bairros situados na face oposta, área pouco habitada (Figura 6). Não houve expansão da doença para novas áreas ao longo do período.

Dos 621 casos notificados, 90,1\% eram residentes na localidade provável de infecção e 58, fora da área de transmissão, e adquiriram LTA em atividades de lazer (39) ou trabalho (19).

No primeiro período epidêmico, em Ilhabela e em São Sebastião, o predomínio de casos deu-se entre os habitantes que residiam no local há menos de 5 anos (62,3\% e 63,5\%, respectivamente) e, em Caraguatatuba e Ubatuba, a freqüência maior foi entre aqueles com mais de 6 anos de moradia (52,9\% e 80,5\%, respectivamente).
No segundo período epidêmico, em todos os municípios predominou os que residiam há mais de 6 anos na localidade ( $\geq 60 \%$ ).

No perfil ocupacional, as categorias de atividade doméstica e estudantes predominaram. No período de 2002-2005, em todos os municípios, evidenciou-se o aumento no percentual de casos associados à construção civil, e redução entre os menores e estudantes.

As formas cutâneas foram predominantes (98,4\%) e a cutâneomucosa representou $1,6 \%$ dos casos. As recidivas foram pouco frequientes $(1,3 \%)$. Na grande maioria $(84,7 \%)$ dos domicílios registrou-se 1 caso de LTA, e em 12,9\% deles, houve 2 a 3 casos.

No período de estudo, foram capturados 2758 flebotomíneos, $51 \%$ no peridomicilio, com predomínio (83\%) de Nyssomyia intermedia.

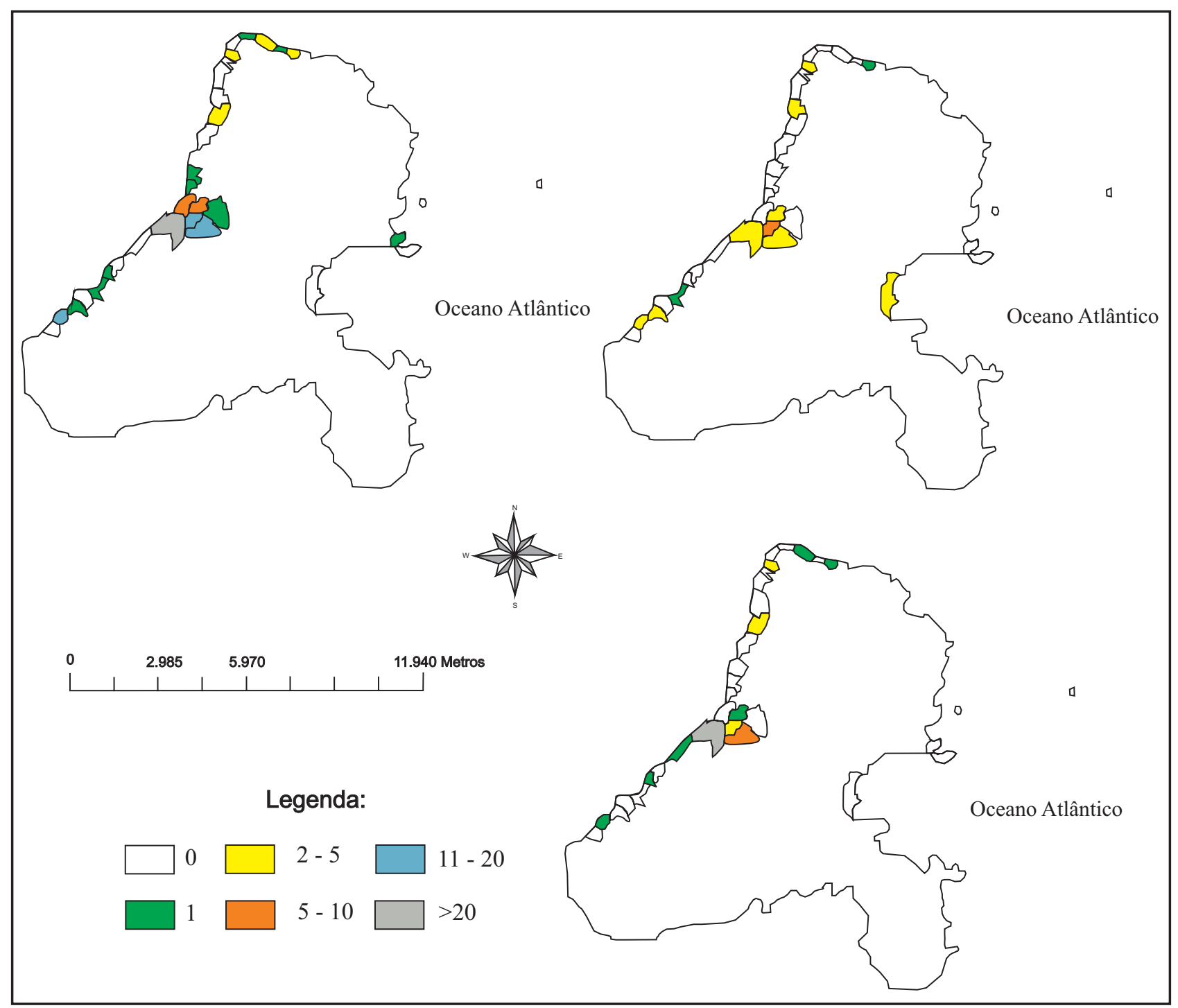

Figura 6 - Freqüência de casos de leishmanioe tegumentar americana, segundo período, município de Ilbabela, Estado de São Paulo, Brasil.

\section{DISCUSSÃO}

A notificação de poucos casos e dispersos de ITA no Litoral Norte, com predomínio em adultos do sexo masculino até meados da década de $1990^{35}$ sugere que a transmissão estava condicionada aos focos naturais, o que explicaria a ausência de surtos epidêmicos durante os desmatamentos da floresta primária, no período de construção da rodovia Rio-Santos ${ }^{13}$.
A partir de 1993, até 2005, novo perfil epidemiológico da LTA foi evidenciado no Litoral Norte Paulista. A endemia manifestou-se descontínua, heterogênea e circunscrita no espaço, com casos isolados e agrupados, onde condições ecológicas estariam provavelmente garantindo a reprodução e circulação dos parasitos, uma vez que locais com concentrações de casos podem atuar como pólos de difusão da infecção, tal como observado por Soares $^{20}$, na Baía da Ilha Grande, Rio de Janeiro. 
0 perfil de transmissão da LTA observado no período de estudo pode ser conseqüente do êxodo rural na década de 1970 e o intenso fluxo migratório ocorrido no litoral, a partir da década de 1980, que levaram ao estabelecimento da população carente nas margens das rodovias e dos núcleos urbanos, em um ecossistema frágil à ação antrópica. Essas mudanças socioeconômicas levam à deterioração do meio ambiente e o aprofundamento das iniqüidades e desigualdades sociais que potencializam o risco de transmissão da LTA em uma dada região, assim como, a exploração do turismo sem as devidas medidas de prevenção, expondo populações suscetíveis a regiões com focos ativos da LTA ${ }^{6}$. Tais circunstâncias foram identificadas na expansão da LTA no Rio de Janeiro, onde as condições necessárias para a manifestação se estabeleceram durante o processo de formação e organização do espaço da cidade, com as maiores incidências nas áreas que se encontrava em processo de consolidação urbana ${ }^{12}$. Por outro lado, nesse estado, em região contígua ao município de Ubatuba, observou-se que a migração pode não ter sido fator preponderante para o desencadeamento de surtos na região, mas sim a presença de roedores silvestres ${ }^{20}$.

No Litoral Norte, a migração parece ter modulado a intensidade da transmissão do agravo. 0 processo de crescimento migratório ocorreu de maneira intensa em três municípios, enquanto em Ilhabela, segundo a Fundação Sistema Estadual de Análise de Dados (SEADE), no período entre 1991 e 1996, houve evasão da população, com saldo do crescimento vegetativo de $195,9 \%$ e do migratório de $-95,9 \%$. Neste município, no segundo período epidêmico, houve redução de $53 \%$ no número de casos, diferentemente dos demais municípios que registraram maior intensidade de transmissão.

A manifestação cíclica neste estudo corrobora o perfil clássico de transmissão de LTA, sugerindo que fatores extrínsecos, relacionados ao macro ambiente poderiam estar favorecendo a transmissão. 0 fenômeno El Nino explicaria em parte este perfil, tal como observado na Colômbia e Costa Rica ${ }^{418}$ e no Brasil, onde se verificou aumentos na incidência de LTA, no primeiro ano de ocorrência do evento ${ }^{23}$. Na Bahia, constatou-se a associação da frequiência e duração deste fenômeno, com a reemergência e comportamento cíclico da leishmaniose visceral ${ }^{8}$.

O sincronismo no início do processo epidêmico e a presença de casos tanto agrupados como isolados no espaço, independentemente das localidades estarem em área mais urbanizada ou mais silvestre, sugere que embora a região apresente características físicas semelhantes, fatores do micro ambiente podem também estar favorecendo o desencadeamento e a expansão da infecção de maneira diferenciada no mesmo município. No Estado de São Paulo, este comportamento foi observado associado ao aumento da densidade do vetor na região do Litoral Sul no período entre 1981 e $1995^{7}$. Na Cidade do Rio de Janeiro e na região de Paraty, a ocorrência simultânea em focos descontínuos, com tendências à propagação e concentração do agravo em novas localidades, foi associada com padrão de transmissão domiciliar ${ }^{12} 20$.

A residência dos pacientes no local provável de infecção sugere transmissão no ambiente doméstico ou peridoméstico, favorecido pela formação de biocenose secundária que preservam os focos naturais entre 0 ambiente primitivo e artificial ${ }^{11}$. 0 tempo de residência por longo período ( $>6$ anos) na área, como ocorreu em Ubatuba no primeiro período epidêmico e em todos os municípios, no segundo, teria favorecido a migração de reservatórios sinantrópicos para o peridomicílio, atraídos por resíduos antrópicos ${ }^{20}$. 0 tempo menor que 5 anos sugere que a introdução de suscetíveis nas áreas de risco, no primeiro momento da epidemia em Ilhabela e São Sebastião, e no segundo período, em Caraguatatuba ( $<1$ ano, 11\%) pode ter influenciado a intensidade dos casos.

A ocorrência de LTA com agregação familiar registrada em residências localizadas isoladamente no interior da mata, a infecção em ambos os sexos e o comprometimento de todas as faixas etárias corroboram com as evidências de que a transmissão esteja ocorrendo em ambiente domiciliar, peri ou intra, tal como observado por outros pesquisadores ${ }^{51217}$.

0 aumento das ocupações ligadas à construção civil, no segundo período epidêmico, pode ser explicado pelo incremento do turismo, especulação imobiliária e da construção de casas de veraneio próximas às áreas de mata, expondo mais esse grupo de trabalhadores. Este, por pertencer também à população de menor poder aquisitivo, é deslocado para a interface entre a franja urbana e o ambiente florestal, onde reside em habitações precárias que propiciam o contato com vetores e reservatórios da LTA, garantindo a manutenção da endemia na área ${ }^{12}$.

Em Ubatuba, entre os casos de LTA contraídos em 2003, $60 \%$ não possuíam trabalhos remunerados, sendo a maioria de nível sócio-econômico precário. Suas moradias apresentavam saneamento básico deficiente, construídas isoladamente ou agrupadas na periferia (a menos de 50m da mata, 86,5\%) e ou dentro da mata. Algumas delas com acesso somente a péé ${ }^{24}$.

Nyssomyia intermedia pode ser considerada o principal vetor da LTA na região, pela predominância nas capturas entomológicas, comportamento antropofílico, encontro de infecção natural por flagelados e pela Leishmania (Viannia) braziliensis, considerada principal agente etiológico da regiã $0^{1617}$.

Caso de infecção humana por Leishmania (Leishmania) amazonensis foi descrito no município de Paraty, $\mathrm{RJ}^{1}$ e em roedores silvestres de Ilhabela ${ }^{21}$. Além disto, foi constatada a infecção experimental de Nyssomyia intermedia por este agente $^{14}$. Assim, alerta-se para a necessidade de diagnósticos diferenciais dos agentes da LTA no Litoral Norte do Estado de São Paulo.

Em suma, a feição epidemiológica da LTA no Litoral Norte parece ter sido modulada por fatores do microambiente, porém pode ter sido exacerbada pelos processos migratórios, manifestando-se por surtos epidêmicos cíclicos. A leishmaniose tegumentar americana nesta região, relaciona-se com a proximidade da mata na interface com 0 ambiente peridoméstico. A ocupação das áreas periurbanas pela população migrante de baixo poder aquisitivo com seus animais domésticos a coloca em condição de vulnerabilidade para adquirir a infecção e também manter e expandir a endemia. 
Por ser área de transmissão recente de LTA, estudos são necessários para melhor compreensão da interação dos ciclos selváticos e domésticos, da real contribuição dos animais domésticos e do homem na manutenção da endemia, bem como, dos fatores que interferem nas variações do micro e macro ambiente. Ressalta-se a importância de estudos da dinâmica da população humana local, de forma a subsidiar o programa de vigilância e controle da LTA no Litoral Norte Paulista.

\section{REFERÊNCIAS}

1. Azeredo-Coutinho RBG, Conceição-Silva F, Schubach A, Cupollilo E, Quintella LP, Madeira MF, Pacheco RS,Valete-Rosalino CM, Mendonça SCF. First report of diffuse cutaneous leishmaniasis and Leishmania amazonensis infection in Rio de Janeiro State, Brazil. Transactions of the Royal Society of Tropical Medicine and Hygiene 101: 735-737, 2007.

2. Basano SA, Camargo ALM. Leishmaniose tegumentar americana: histórico, epidemiologia e perspectivas de controle. Revista Brasileira de Epidemiologia 7: 328-337, 2004.

3. Brito M, Casanova C, Mascarini LM, Wanderley DMV, Corrêa FMA. Plebotominae (Diptera: Psychodidae) em área de transmissão de leishmaniose tegumentar americana no litoral norte do estado de São Paulo, Brasil. Revista da Sociedade Brasileira de Medicina Tropical 35: 431-437, 2002.

4. Chaves LF, Pascual M. Climate cycles and forecast of cutaneous leishmaniasis, a nonstationary vector-borne disease. Plos Medicine 3:1320-1328, 2006.

5. Condino MLF, Toia RM, Azevedo CC. Aspectos epidemiológicos da leishmaniose tegumentar americana no município de Ubatuba, litoral norte, São Paulo - Brasil, 1993 - 2003. Boletim Epidemiológico Paulista 1: 6-7, 2004.

6. Desjeux P. Leishmaniasis: current situation and new perspectives. Comparative Immunology Microbiology Infectious Diseases 27: 305-318, 2004.

7. Domingos MF. Aspectos da leishmaniose tegumentar americana na região do Vale do Ribeira, Estado de São Paulo, Brasil, período de 1981 a 1995. Dissertação de Mestrado, Faculdade de Saúde Pública, Universidade de São Paulo, São Paulo, SP, 1997.

8. Franke CR, Ziller M, Staubach C, Latif M. Impact of the El Niño/Southern oscillation on visceral leishmaniasis, Brazil. Emerging Infections Diseases 8: 914-917, 2002.

9. Fundação Sistema Estadual de Análise de Dados (SEADE). Sistema de informações dos municípios paulistas 1993-2005 [on line]. Disponível em: http://www.seade. gov.br/produtos/imp/imp.php. Acesso em $21 \mathrm{dez} 2005$.

10. Galati EAB. Morfologia e taxonomia. Classificação de Phlebotominae. In: Rangel EF, Lainson R (eds) Flebotomíneos do Brasil. Editora da Fundação Oswaldo Cruz, Rio de Janeiro, p.23-51, 2003.

11. Gomes AC. Mecanismo e significado epidemiológico da domiciliação. Revista de Saúde Pública 20:385-390, 1986.
12. Kawa H, Sabroza PC. Espacialização da leishmaniose tegumentar americana na cidade do Rio de Janeiro. Cadernos de Saúde Pública 18: 853-865, 2002.

13. Marzochi MCA. Leishmanioses no Brasil: as leishmanioses tegumentares. Jornal Brasileiro de Medicina 63: 82-104, 1992.

14. Paiva BR, Secundino NFC, Pimenta PFP, Galati EAB, Andrade-Junior HF, Malafronte RS. Padronização de condições para a deteç̧ão de DNA de Leishmania spp. em flebotomíneos (Diptera, Psychodidae) pela reação em cadeia da polimerase. Cadernos de Saúde Pública 23:87-94, 2007.

15. Petney TN. Environmental, cultural and social changes and their influence on parasite infectious. International Journal for Parasitology 31: 919-993, 2001.

16. Pita-Pereira D, Alves CR, Souza MB, Brazil RP, Bertho AL, Barbosa AF, Britto CC. Identification of naturally infected Lutzomyia intermedia and Lutzomyia migonei with Leishmania (Viannia) braziliensis in Rio de Janeiro (Brazil) revealed by a PCR multiplex non-isotic hybridisation assay. Transactions of the Royal Society of Tropical Medicine and Hygiene 99: 905-913, 2005.

17. Rangel EF, Lainson R. Ecologia das leishmanioses. Transmissores de leishmaniose tegumentar americana. In: Rangel EF, Lainson R (eds) Flebotomíneos do Brasil. Editora da Fundação Oswaldo Cruz, Rio de Janeiro, p.291-309, 2003.

18. Rojas CA. An ecosystem approach to human health and the prevention of cutaneous leishmaniasis in Tumaco, Colombia. Cadernos de Saúde Pública 17 (supl): 193-200, 2001.

19. Secretaria de Estado do Meio Ambiente (SEMA). Coordenadoria de Planejamento Ambiental Estratégico e Educação Ambiental (CPLEA). Decreto SMA nº49.215, de 7 de dezembro de 2004. Zoneamento Ecológico-Econômico do Litoral Norte. Coordenadoria de Planejamento Ambiental Estratégico e Educação Ambiental, Secretaria de Estado do Meio Ambiente, São Paulo, 2005.

20. Soares VB. Proposta de Vigilância de leishmaniose tegumentar em nível local. Análise de indicadores para região endêmica da Mata Atlântica no estado do Rio de Janeiro de 1990 a 2004. Dissertação de Mestrado, Escola Nacional de Saúde Pública. Rio de Janeiro, RJ, 2006.

21. Tolezano JE, Taniguchi HH, Bisugo MC, Araújo MFL, Cunha EA, Elias CR, Larosa R. Occurrence of natural Leishmania (Leishmania) infection in Proechimys heringi in an endemic area of human and canine American cutaneous leishmaniasis due to Leishmania (Viannia) braziliensis in Ilhabela, São Paulo, Brasil. In: Resumos da XII Jornada Paulista de Parasitologia da Sociedade Brasileira de Parasitologia. II Jornada Educacional e Biomédica da Superintendência de controle de Endemias, Taubaté p. 9, 1998.

22. Tolezano JE, Taniguchi HH, Elias CR, Larosa R. Epidemiologia da leishmaniose tegumentar americana (LTA) no Estado de São Paulo. III. Influência da ação antrópica na sucessão vetorial da LTA. Revista do Instituto Adolfo Lutz 60: 47-51, 2001.

23. Tolezano JE, Taniguchi HH, Hiramoto RM, Mesquita RT, Teixeira D, Aureliano DP, Tolezano LFC. El Niño southern oscillation e a leishmaniose tegumentar americana no Brasil, 1990-2004. In: anais do XLIII Congresso Sociedade Brasileira de Medicina Tropical, II Encontro de Medicina Tropical dos Países de Língua Portuguesa e I Encontro da Sociedade Brasileira de Medicina de Viagens. Campos do Jordão, p.132, 2007.

24. Vanzeli AC. Contribuição ao estudo de indicadores sócio-ambientais para o controle da leishmaniose tegumentar americana. Dissertação de Mestrado, Universidade de Taubaté, Taubaté, 2006. 